\title{
CORRECTION
}

\section{Correction to: Neurocritical Care Society Guidelines Update: Lessons from a Decade of GRADE Guidelines}

Lori K. Madden ${ }^{*}$, Venkatakrishna Rajajee ${ }^{2}$, Theresa Human ${ }^{3}$, Mark S. Wainwright ${ }^{4}$, Mary Guanci ${ }^{5}$, Shraddha Mainali ${ }^{6}$, Shaun Rowe ${ }^{7}$, Diane McLaughlin ${ }^{8}$, John Lunde ${ }^{9}$, Abhijit Lele ${ }^{10}$ and Herb Fried ${ }^{11}$

(c) 2021 Springer Science+Business Media, LLC, part of Springer Nature and Neurocritical Care Society

\section{Correction to: Neurocrit Care https://doi.org/10.1007/s12028-021-01375-1}

This article was updated to correct the legend to Figure 2.

\section{Author details}

${ }^{1}$ Center for Nursing Science, University of California Davis Health, 2315 Stockton Blvd, North Addition 3015, Sacramento, CA 95817, USA. ${ }^{2}$ Departments of Neurosurgery and Neurology, University of Michigan, Ann Arbor, MI, USA. ${ }^{3}$ Cumberland Pharmaceuticals, Nashville, TN, USA. ${ }^{4}$ Division of Pediatric Neurology, University of Washington, Seattle, WA, USA. ${ }^{5}$ Neuroscience Intensive Care Unit, Massachusetts General Hospital, Boston, MA, USA. ${ }^{6}$ Department of Neurology, Virginia Commonwealth University, Richmond, VA, USA. ${ }^{7}$ Department of Clinical Pharmacy and Translational Science, College of Pharmacy, The University of Tennessee Health Science Center, Knoxville, TN, USA. ${ }^{8}$ Departments of Neurology and Neurocritical Care, University of Florida Health, Jacksonville, FL, USA. ${ }^{9}$ Division of Critical Care, Intensive Care Consortium/Orange Park Medical Center, Orange Park, FL, USA. ${ }^{10}$ Departments of Neurosurgery and Anesthesiology and Pain Medicine, University of Washington, Seattle, WA, USA. ${ }^{11}$ Division of Neurosurgery, Denver Health Medical Center, Denver, CO, USA.

\section{Publisher's Note}

Springer Nature remains neutral with regard to jurisdictional claims in published maps and institutional affiliations.

Published online: 7 December 2021

\footnotetext{
*Correspondence: Ikmadden@ucdavis.edu

${ }^{1}$ Center for Nursing Science, University of California Davis Health, 2315 Stockton Blvd, North Addition 3015, Sacramento, CA 95817, USA

Full list of author information is available at the end of the article
}

The original article can be found online at https://doi.org/10.1007/ s12028-021-01375-1.

\section{Springer}

